\title{
СОВРЕМЕННЫЕ МЕТОДЫ КОНТРОЛЯ ГЛИКЕМИИ У ДЕТЕЙ С САХАРНЫМ ДИАБЕТОМ 1 ТИПА В РЕАЛЬНОЙ КЛИНИЧЕСКОЙ ПРАКТИКЕ
}

\author{
А.Е. Красновидова, А.М. Римская, А.В. Витебская \\ ФГАОУ ВО «Первый МГМУ им. И.М. Сеченова» Минздрава России (Сеченовский университет)
}

\begin{abstract}
АКТУАЛЬНОСТЬ. Ежедневный контроль уровня глюкозы в крови является неотъемлемым компонентом терапии сахарного диабета 1 типа (СД1) у детей. Согласно рекомендациям ISPAD 2018, частота измерения гликемии должна составлять 6-10 раз в сутки. В связи с появлением широкого спектра устройств для самостоятельного измерения глюкозы крови, таких как глюкометры, устройства для мониторинга гликемии (УМГ), пациенты стали чаще чередовать их использование.

ЦЕЛЬ: изучить использование современных методов контроля гликемии и их комбинирование у детей с СД1 в реальной клинической практике

МАТЕРИАЛЫ И МЕТОДЫ: В проспективное когортное исследование было включено 104 ребенка $11,5 \pm 4,2(1,5-17,0)$ лет, с длительностью СД1 4,92 $\pm 0,7(0,1-16,0)$ лет, гликированным гемогло-

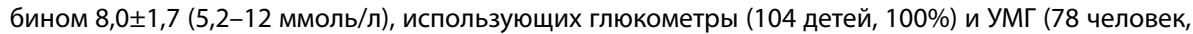
75\%). Пациенты или их родители ответили на вопросы анкеты о возрасте, длительности СД1, количестве измерений гликемии в сутки с помощью различных устройств, предпочтениях и трудностях при их использовании.
\end{abstract}

РЕЗУЛЬТАТЫ. Большинство пациентов $(49(47,1 \%))$ постоянно использует УМГ $(46(44,2 \%)$ из них - флеш-мониторинг), 6 (5,8\%) использует их половину времени, 23 (22,1\%) - реже, $26(25,0 \%)$ пациентов никогда ими не пользовались.

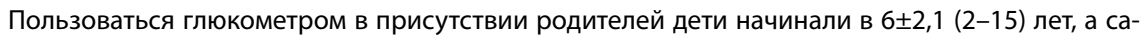

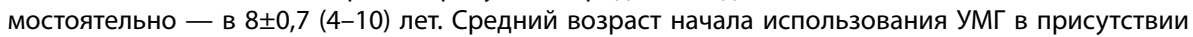

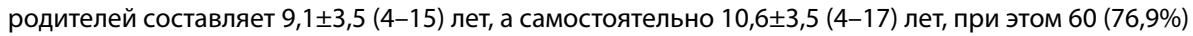
детям родители помогают устанавливать сенсор, а 41 (52,6\%) - снимать.

Пациенты сообщили, что они проводят измерение гликемии с помощью глюкометра в отсутствие УМГ 7,0 4,2 (1-10) раз в сутки. При использовании УМГ 65 (83,3\%) пациентов сообщили, что проводят измерения более 10 раз в сутки.

Дополнительные измерения гликемии с помощью глюкометра при использовании УМГ проводят 27 (34,6\%) пациентов при высоких значениях гликемии, 29 (37,2\%) - при низких; 3 (3,8\%) при несоответствии самочувствия и показателей глюкометра/УМГ; 3 (3,8\%) - при переходе на новый глюкометр; 8 (10,3\%) - в первые сутки после установки нового сенсора.

Среди причин, по которым дети могли бы отказаться от использования глюкометра, 67 (64,4\%) указали погрешности в измерениях, 48 (46,2\%) - трудность контроля гликемии во время сна, 44 (42,3\%) - воспалительные реакции в местах проколов, 40 (38,5\%) - боль при проколе, 32 (30,8\%) - потребность в большой капле крови, 23 (22,1\%) - большой размер устройства, $21(20,2 \%)$ - цена.

Среди причин возможного отказа от использования УМГ 47 пациентов (60,3\%) указали погрешности в измерениях, 36 (46,2\%) - появление уплотнений в местах установки, 31 (39,7\%) воспалительная реакция на адгезивные материалы, 26 (33,3\%) - цена, 24 (30,8\%) - дискомфорт при ношении устройства, 22 (28,2\%) - недостаточная фиксация прибора к коже, 8 (10,3\%) - заметность.

Выводы. Пациенты, использующие УМГ, чаще проводят самоконтроль, что свидетельствует о более качественном контроле заболевания. Средний возраст начала самостоятельного использования глюкометров оказался ниже, чем УМГ, несмотря на то, что второе использовать гораздо проще. Возможно, это связано с относительно недавним массовым использованием УМГ.

Большинство пациентов комбинирует использование глюкометра и УМГ, сочетая и дополняя эти методы. 